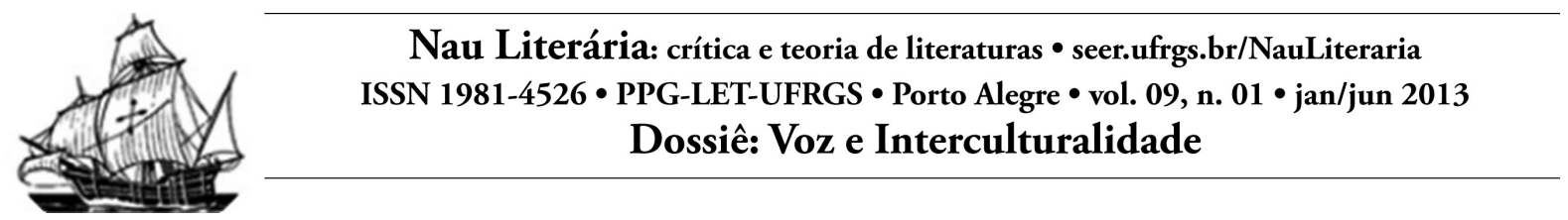

\title{
DEBATE REGRADO- DOMÍNIO DO ARGUMENTAR TRABALHANDO COM A ORALIDADE EM UMA TURMA DO $3^{\circ}$ ANO DO ENSINO FUNDAMENTAL
}

Jane Engel CORRÊA (UNISINOS) ${ }^{1}$

Resumo: Este artigo tem como objetivo demonstrar que a língua oral precisa ser ensinada, assim como a língua escrita e que é possível o trabalho com gêneros textuais também do domínio do argumentar nas séries iniciais. A atividade relatada pertence ao projeto "Por uma formação continuada e cooperativa para o desenvolvimento do processo educativo da leitura e produção textual escrita no Ensino Fundamental", desenvolvido junto ao PPGLA da UNISINOS. Este projeto desenvolve a noção de projetos didáticos de gênero (GUIMARÃES e KERSCH, 2012), que alia o ensino de gêneros do discurso a práticas sociais. Foi escolhido um gênero oral, o debate regrado, pois a turma trazia na oralidade diariamente seus anseios e angústias em função da violência que presenciavam, e, ainda não conseguiam argumentar por escrito suas posições.

PALAVRAS-CHAVE: Oralidade. Gêneros textuais. Argumentação. Séries iniciais.

\begin{abstract}
This article aims to demonstrate that the oral language needs to be taught, as well as written language and that it is possible to work with genres also the domain of the argument in the early grades. The reported activity belongs to the project "Towards a cooperative and continuing education for the development of the educational process of reading and writing textual production in Elementary Education," developed by the PPGLA UNISINOS. This project develops the notion of educational projects gender (Guimarães and Kersch, 2012), which combines the teaching of speech genres to social practices. Was chosen a genre oral debate regimented as the class brought in their daily oral longings and anxieties due to the violence that presenciavam, and still could not argue their positions in writing.
\end{abstract}

KEYWORDS: Orality. Genres. Argument. Initial series.

\footnotetext{
${ }^{1}$ Jane Engel Corrêa -Unisinos-Universidade do Vale do Rio dos Sinos-São Leopoldo- RS-Brasil-

Professora Graduada em Letras Português pela Unsisinos/2004, com Pós-Graduação em Língua Portuguesa pela UNICID/2012, Pesquisadora Bolsista do Observatório de Educação do PPGL da Unisinos. Atua como professora pela SMED/Novo Hamburgo e pela Rede Pública do Estado do Rio Grande do Sul. E-mail do autor:jengelcorrea@gmail.com.
} 


\section{Introdução}

O projeto didático de Gênero que resultou neste artigo comprova que todos os gêneros textuais são possíveis de serem trabalhados em qualquer série escolar, independente das características do mesmos. Claro que eles precisam ser adaptados à realidade de cada turma e ter objetivos específicos dentro da proposta pedagógica que se pretende para aquele grupo de alunos.

De acordo com os Parâmetros Curriculares Nacionais de $1^{\circ}$ ao $5^{\circ}$ ano (BRASIL, 1997), ensinar a língua oral exige ação pedagógica que venha a garantir reflexão sobre a língua, respeito pelas formas de expressão oral e atividades que venham proporcionar o saber ouvir, refletir e argumentar.

A escola, através dos educadores, deve refletir cada vez mais sobre o seu papel social e procurar desenvolver habilidades argumentativas, sejam elas orais ou escritas, e também possibilitar aos educandos a aprendizagem de diferentes gêneros textuais e práticas de linguagens dentro de uma perspectiva sociointeracionista, adotando também a oralidade como objeto de ensino.

\section{O ensino da oralidade}

Ensinar a oralidade na escola não é ensinar a fala cotidiana, porque esta já pertence ao indivíduo, mas envolve o aprendizado da linguagem formal. Por isso, como qualquer outro conteúdo curricular, deve ser ensinada na escola de forma planejada e sistematizada.

Conforme Schneuwly \& Dolz, (2004), há uma queixa entre os educadores de que os alunos não conseguem tomar a palavra em público, posicionar-se, argumentar com seus pares. E esta é uma realidade que pode ser modificada, se os professores proporcionarem momentos elaborados, com planejamento específico para a utilização do gênero oral no cotidiano escolar.

O que se vê em grande parte das salas de aula, no ensino de Língua Materna, é grande ênfase nos gêneros escritos, e desmerecimento aos gêneros orais. Como cita Luis Antônio Marchuschi, "os gêneros textuais falados não possuem ainda estudos em grande abrangência" (MARCHUSCHI, 2008, p.187). No entanto, é muito importante trabalhar a oralidade na escola a partir do ensino de um gênero, pois é uma atividade de linguagem que pode contribuir para que o educando possa expor suas opiniões, pontos de vista e também construção de novos conhecimentos, já que o grupo irá aprender em conjunto a falar e ouvir o outro.

As capacidades linguísticas de ler, escrever, falar de acordo com a norma culta e ouvir com compreensão não acontecem sem serem ensinadas, utilizando uma organização metodológica, capaz de dar conta das necessidades dos estudantes, porque qualquer atividade precisa fazer sentido para o aluno, precisa estar conectada a uma prática social.

De acordo com os Parâmetros Curriculares Nacionais de $1^{\circ}$ ao $5^{\circ}$ ano (BRASIL, 1997), ensinar a língua oral exige ação pedagógica que venha a garantir reflexão sobre a 
língua, respeito pelas formas de expressão oral e atividades que venham proporcionar o saber ouvir, refletir e argumentar.

Também conforme os PCNs(BRASIL,1998), a escola precisa dar atenção a modalidade oral da língua, sendo necessário um conjunto de atividades que deem conta desse ensinar.

\footnotetext{
...cabe à escola ensinar o aluno a utilizar a linguagem oral no planejamento e realização de apresentações públicas: realização de entrevistas, debates, seminários, apresentações teatrais etc. Trata-se de propor situações didáticas nas quais essas atividades façam sentido de fato, pois é descabido treinar um nível mais formal da fala, tomado como mais apropriado para todas as situações. (p. 25)
}

Quando é oportunizado às crianças um espaço para falar, dialogar com o professor e colegas sobre diversos assuntos, começa uma mudança na estrutura da sala de aula, pois não é apenas a voz do professor, mas os alunos começam a intervir porque precisam ser ouvidos, precisam opinar. Estes alunos querem, de uma maneira ou de outra, mostrar que sabem de fatos de que o professor não é sabedor.

Sendo assim, a partir do interesse dos alunos e daquilo que fazia parte do cotidiano daquele grupo, surgiu o tema que originou o trabalho com o gênero textual "debate regrado" em uma turma de $3^{\circ}$ ano do Ensino Fundamental. O assunto "A violência no Bairro" já era trazido diariamente para a sala de aula, através de relatos informais dos acontecimentos vividos por aquele grupo de crianças sujeitas a uma realidade que as fazia sentirem-se incomodadas e inseguras, visto que se inserem em uma comunidade sujeita a grandes índices de violência.

\section{Debate Regrado- A argumentação através da oralidade}

Definido como "a exposição da razão em defesa de uma opinião contra um argumento" pelo Dicionário de Gêneros Textuais (COSTA, 2012, p.94), o debate permite expor livremente nossas ideias, mas também exige que saibamos respeitar as opiniões dos outros, sendo uma experiência enriquecedora para a sala de aula, pois além do desenvolvimento da linguagem oral é um exercício de cidadania.

No debate regrado, é preciso que se estabeleçam regras, os objetivos, o tempo limite para a participação de quem está de posse da palavra, pois só assim se dará uma comunicação efetiva com os demais interlocutores, possibilitando $\mathrm{o}$ ato responsivo dos mesmos (BAKHTIN, 2003, p.294). Mesmo sendo usada a fala para sua constituição, o debate regrado 
é classificado por Bakhtin (2003) como um gênero secundário porque exige a sistematização de uma sequência didática.

É preciso que se reconheça que a escola é e necessita continuar sendo um espaço democrático que visa a formação de sujeitos reflexivos e críticos e que estão sendo formados para atuarem socialmente e serem capazes da transformação da realidade social.

Já faz parte do cotidiano dos alunos "debater", posicionar-se a respeito de algum assunto, mesmo que sejam crianças. O texto oral deve ser ensinado (DOLZ, SCHNEUWLY, PIETRO, 2004). Não basta apenas ter uma opinião sobre um assunto, mas é preciso saber expor, falar sobre a opinião. O debate amplia a capacidade dos alunos de encontrar uma solução a partir da escuta aos outros, sendo que o objetivo do trabalho com os gêneros do domínio do argumentar é encontrar, a partir do raciocínio coletivo, soluções viáveis para situações colocadas que estão sendo discutidas.

Também o debate, além de desenvolver as capacidades argumentativas, contribui para cultivar valores como respeito pela opinião do outro e cuidado com o ato da fala, pois de acordo com Schneuwly e Dolz (2004):

[...] saber falar, não importa em que língua, é dominar os gêneros que nela emergiram historicamente, dos mais simples aos mais complexos (SCHNEUWLY e DOLZ, 2004, p.138).

Em "Relato da elaboração de uma sequência: o debate público", os autores Joaquim Dolz, Bernard Schneuwly e Jean François de Pietro confirmaram através da elaboração e aplicação de uma sequência didática sobre o gênero debate, que as crianças desde cedo produzem intervenções, tomam posição e sustentam argumentos (SCHNEUWLY \& DOLZ, 2004,p.255).

Não há como saber falar, saber posicionar-se se não for proporcionada aos alunos esta possibilidade. E se os alunos não conseguem organizar sua fala para argumentar e opinar, não conseguirão participar com sucesso de determinadas práticas sociais.

De acordo com Parâmetros Curriculares Nacionais de Língua Portuguesa, o domínio da língua possibilita a inserção e participação social, já que é com comunicação eficiente, há acesso a informação, há a possibilidade de expressar diferentes pontos de vista e partilhar visões diferentes sobre o mundo que rodeia os alunos (BRASIL, 1997).

A escola também precisa se constituir em ambiente que respeite a voz, e as diferenças, mas precisa ensinar ao educando o uso da língua adequando-a a diferentes situações comunicativas, fazendo com que o aluno possa fazer uso da língua de forma competente (BRASIL, 1997)

\section{Transformando a oralidade em aprendizagem- Relato de um desafio}


A experiência aqui relatada surgiu como atividade do Projeto "Por uma formação continuada e cooperativa para o desenvolvimento do processo educativo da leitura e produção textual no Ensino Fundamental", desenvolvido junto ao Programa de Pós Graduação em Linguística Aplicada da Universidade do Vale do Rio dos Sinos-Unisinos, com apoio do Programa Observatório da Educação da CAPES. Este projeto, com base sobretudo no trabalho desenvolvido por Dolz e Schneuwly (2004), desenvolve a noção de projetos didáticos de gênero- PDG (Guimarães e Kersch, 2012), que aliam o ensino de gêneros do discurso (Bakhtin, 2003) a práticas sociais.

Cabe ressaltar que há uma outra versão deste artigo que será publicada nos anais do IV Simpósio Mundial de Estudos de Língua Portuguesa (Simelp), intitulado "Língua Portuguesa: ultrapassando fronteiras, unindo culturas" e realizado na Universidade Federal de Goiás (UFG), em Goiânia, de 02 a 05 de Julho de 2013, em que fui compartilhar a aplicação deste PDG(Projeto Didático de Gênero).

Como dentro daquele grupo, eu era a única que possuía uma turma de $3^{\circ}$ ano, pois os participantes eram, em sua maioria, professores das séries finais do ensino fundamental, começaram as dúvidas de como se daria a produção textual, se meus alunos ainda não estavam com fluência em leitura e escrita. Poucos, naquele momento, entendiam o que era escrever um texto, e as produções, em sua maioria, eram feitas coletivamente.

Então, como as propostas dentro da formação são pensadas em grupo, surgiu a ideia de trabalhar com um gênero oral, e seguindo a proposta de agrupamento de gêneros de Schneuwly e Dolz(2004), pensamos no "debate regrado".

Naquele momento comecei a me apropriar de algumas leituras que precisavam comprovar a tese de que podemos iniciar com diferentes gêneros desde o princípio da vida escolar de nossos alunos. Precisava me despir de alguns conceitos e também preconceitos em relação ao ensino da Língua Portuguesa. Fui procurar conhecer a proposta de agrupamentos de gêneros textuais, trazida por Schneuwly e Dolz de que o ideal é de cada agrupamento seja trabalhado em todos os níveis de escolaridade (SCHNEUWLY e DOLZ, 2004, p. 62).

É sabido que a criança, desde pequena, participa do mundo ao seu redor e aprende a argumentar com seus familiares, pois desde um brinquedo que quer ou um passeio que quer fazer, ela precisa reforçar argumentos para convencer daquilo que pede. Então, por que continuar apenas trazendo para as aulas de língua portuguesa o texto argumentativo nas séries finais do ensino fundamental ou como em alguns casos somente no ensino médio? Essa foi a ideia que me moveu naquele momento.

Ao ser trazida a proposta em sala de aula, os alunos ficaram motivados porque iriam fazer parte de uma situação de aprendizagem inovadora, até então naquele ambiente. Informei aos alunos que eles iriam aprender uma nova forma de texto e que não seria escrito, e, sim, oral. Expliquei que nós precisaríamos de alguns recursos, tais como filmadora, televisão.

Questionei se eles sabiam o que era um debate. Alguns disseram que já tinham visto na televisão (se referiam ao debates políticos em época de campanha eleitoral). Procuramos juntos no dicionário o significado da palavra debate e, em conjunto, encontramos o que era mais adequado. 
Surgiu então a produção textual inicial, no caso, o debate inicial. A situação de produção textual inicial está baseada nos estudos dos professores Dolz e Schneuwly(2004), que estudaram uma forma de ensinar a particularidade dos diversos gêneros, através de um modelo didático com o fim de compreender as características de cada gênero e a relação entre os gêneros trabalhados na escola, assim como também, os gêneros fora dela, através da sequência didática (SD) que consiste em o professor apresentar a situação (gênero) para os alunos, expondo o nome do gênero textual a ser trabalhado. Em seguida os alunos realizam a primeira produção textual. Desta forma o professor irá verificar os conhecimentos que os alunos têm sobre o gênero e planejará as atividades que serão trabalhadas pelos alunos ao longo da sequência didática.

A produção inicial é fundamental na aplicação do Projeto Didático de Gênero- PDG, para a elaboração dos meios necessários para os alunos atingirem o texto final com eficiência. $\mathrm{O}$ professor deverá trabalhar com diversos exercícios e atividades para que dominem o gênero escolhido. Essas atividades deverão ser realizadas por módulos ou oficinas e possibilitar aos alunos que construam seus próprios conhecimentos e interajam socialmente com os colegas.

[...] os módulos ou oficinas a serem desenvolvidas em cada projeto pedagógico proposto trarão atividades de leitura que levarão à produção textual. Decorre daí a criação da noção de projeto didático de gênero(PDG)como um guarda-chuva para, a partir de uma escolha temática ou uma demanda da turma, trabalhar-se um mais gêneros em um dado espaço de tempo, sempre com a preocupação de relacioná-lo a uma dada prática social (GUIMARÃES e KERSCH, 2012,P.23).

Foi realizada a filmagem que aconteceu no momento da fala que se constituiu na produção inicial do debate. Fiz o papel de mediadora, enquanto os alunos iam respondendo a perguntas que eles mesmos faziam aos colegas e também perguntas que eu fazia para eles, referente à violência no bairro. Questionava-os sobre quais os motivos de tantos assassinatos, roubos, que mais era temido por eles, o que faziam quando estavam com muito medo, se já tinham presenciado algum assalto ou morte, se existia alguma forma de acabar com tantos assassinatos.

Em nenhum momento houve a interrupção da filmagem e as falas surgiam com naturalidade. Nós apenas tínhamos combinado que, para falar, eles deveriam levantar a mão e aguardar a vez de falar. Também precisariam ouvir o que os colegas falavam e que estariam sendo filmados

A ansiedade por responder às perguntas era grande, e, em muitas ocasiões, eles queriam trazer depoimentos das vivências que tinham sobre o assunto que fazia parte do cotidiano deles. Cabe ressaltar que tentei ser o mais imparcial possível nos depoimentos que traziam, mas algumas vezes tive que intervir e pedir que retornassem ao assunto.

A produção inicial teve duração de vinte minutos e na próxima aula começaram as sequências de oficinas para dar seguimento ao ensino do gênero, pois "Cada gênero necessita 
de um ensino adaptado, pois apresenta características distintas" (SCHNEUWLY e DOLZ, 2004, p.120).

O Projeto Didático de Gênero continuou e começamos a realizar as oficinas. Na primeira oficina trouxe para eles o vídeo ${ }^{2}$ de um debate. Este debate foi retirado do YouTube de um programa de televisão. O tema do debate era "Bullying e violência nas escolas" (HORIZONTE DEBATE, 2011) exibido em 04/05/2011 pelo Programa Horizonte Debate. O assunto abordado se assemelhava ao assunto com o qual estávamos trabalhando, pois trazia questões de violência.

Logo após, começamos a estudar sobre o gênero. Entreguei para eles um texto (escrito), uma cópia para cada um, que explicava as regras de um debate, sendo esta a segunda oficina. No momento que líamos o texto que explicava como precisava ser um debate regrado, relembrávamos como tinha sido o nosso debate inicial, ou seja, a nossa produção textual inicial, pois os alunos tinham assistido à filmagem antes de terem acesso ao texto

No dia seguinte, na aula de Língua Portuguesa, fizemos a terceira oficina. Trouxe para eles o xerox de uma notícia veiculada em um jornal em nível estadual que trazia como manchete "Endereço da violência- A rua dos homicídios em Novo Hamburgo" (COELHO, 2012). A notícia se referia ao grande número de homicídios ocorridos em um pequeno período de tempo no bairro e especificamente em uma única rua. A leitura do texto foi feita em voz alta, ora por mim, ora por eles. E, como a notícia era longa, líamos em partes e discutíamos em conjunto o que estava sendo relatado. $O$ texto serviria para terem mais argumentos quando acontecesse o debate final.

Na semana seguinte começamos a nos preparar para a produção final. Já estávamos na quarta oficina. Foi escolhido coletivamente quem seria o mediador, os debatedores e também as perguntas que norteariam as discussões durante o debate e quem seria participante do debate daqueles que ficariam na plateia.

Feitas as escolhas, os alunos tiveram um tempo para se preparem para a filmagem do debate. As respostas para as perguntas foram sendo elaboradas pelos alunos que seriam debatedores. Os demais alunos ajudavam os que seriam os debatedores e o mediador a formularem perguntas e respostas adequadas.

Na quinta oficina, aproveitamos o momento de preparo das respostas dos debatedores para analisarmos a fala dos debatedores e refletirmos sobre a língua padrão e a língua não padrão. Como estávamos estudando um gênero oral, fiz comparações oralmente de algumas variedades da língua. Utilizei algumas falas deles feitas no primeiro debate e fizemos conjuntamente uma adequação utilizando uma linguagem mais formal.

Expliquei que, mesmo não sendo um texto escrito, eles precisariam falar corretamente, até porque esse debate seria filmado e visto por outras pessoas na escola, servindo de exemplo para um grande debate que faríamos com toda a escola sobre o mesmo assunto.

O dia da produção final do debate foi esperado com grande ansiedade. Preparamos o ambiente da sala de aula em primeiro lugar. As classes foram retiradas e colocadas em outro

\footnotetext{
${ }^{2} \mathrm{O}$ vídeo pode ser encontrado no link: "https://www.youtube.com/watch?v=fpjZ_kDI_So"
} 
espaço. As cadeiras foram dispostas de forma que eles ficassem sentados como se estivessem em um programa de televisão. E à frente estavam sentados em um semicírculo os debatedores e o mediador de frente para a plateia que eram os demais alunos.

O momento foi novamente filmado. O que mais surpreendeu é que, mesmo eles tendo as perguntas já elaboradas e sabendo o papel que cada um faria naquela situação, eles conseguiram improvisar e trazer ao final novos questionamentos com relação à violência. Uma aluna trouxe uma questão que ainda não havíamos discutido: "As crianças que agem com violência na escola, poderão se tornar violentas na vida adulta, mas só agem assim porque são maltratadas pelos familiares em casa."

O que preciso informar é que estas crianças tinham entre 8 e 9 anos. Isto demonstra que, muitas vezes, nós, professores, subestimamos a capacidade argumentativa e questionadora que elas possuem.

A situação que seguiu após o término de debate, foi que, no dia seguinte, fomos assistir aos dois debates e então avaliamos conjuntamente a produção final através de uma grade avaliativa, constituindo-se, assim, a sexta oficina, que contemplava os critérios necessários para a realização deste gênero textual. Ao final da avaliação, percebemos que o debate foi bem realizado, pois obteve êxito na maioria dos critérios.

\section{Considerações Finais}

O projeto, confirmou a hipótese, de que é necessário e possível diversificar as aulas de Língua Materna e, que, mesmo no início da vida escolar, os alunos devem ser inseridos na diversidade de gêneros textuais. $O$ professor não precisa ficar esperando um determinado período da etapa letiva para tornar conhecido pelos alunos determinados textos. Não precisamos nos deixar dominar por um currículo que nos faz ensinar sempre da mesma forma e tendo como predominância a gramática e a ortografia. (GUIMARÃES, CASTILHOS, DREY, 2008).

Também é preciso que a oralidade se torne mais presente na vida escolar, pois não é porque o aluno chega na escola falando, que ele já domina a língua padrão e faz uso da palavra para se posicionar com argumentação necessária, se tornando participante ativo da sociedade, pois há uma popularização dos gêneros escritos na maioria das salas de aula e descaso dos gêneros orais.

Por sua vez, a escola não pode ficar isolada da vida como um todo e a aprendizagem textual deve interagir com uma prática social, independente se esse texto é da esfera escrita ou oral. O Projeto Didático de Gênero-PDG, faz esta ligação entre produção textual e a sua utilização no dia a dia do aluno, porque não há mais como termos apenas os gêneros escolares fazendo ligação entre o aprender e o ensinar, pois o aprender precisa fazer sentido para o aluno e ele tenha o desejo de aprender. 
Portanto, a escolha de um gênero oral, para ensinar a argumentação veio dar conta do que os alunos já estavam fazendo, mas em forma de relatos. Eles discutiam a violência e já tinham uma percepção das causas da violência. E foi isto que fez os objetivos terem sido alcançados para aprendizagem de um gênero textual novo.

\section{Referências Bibliográficas:}

BAKTIN, Michael. Estética da Criação Verbal. São Paulo: Martins Fontes,2003.

BAZERMAM, Charles. Gêneros Textuais - Tipificação e Interação. São Paulo:Cortez,2006.

BRASIL. Secretaria de Educação Fundamental. Parâmetros Curriculares Nacionais: Língua Portuguesa, área de linguagens, códigos e suas tecnologias. $1^{\circ}$ ao $5^{\circ}$ ano, Brasília: MEC/SEF. 1997.

COELHO, Alisson. Rua concentra $20 \%$ dos homicídios em Novo Hamburgo, no Vale do Sinos: Nove dos 44 casos registrados no quadrimestre ocorreram na Rua da Divisa. Zero. Hora, 09 de jun. 2012, Policial/Notícias. Disponível em: Rua concentra 20\% dos homicídios. em Novo Hamburgo, no Vale do SinosNove dos 44 casos registrados no quadrimestre ocorreram na Rua da Divisahttp://zerohora.clicrbs.com.br/rs/policia/noticia/2012/06/ruaconcentra-20-dos-homicidios-em-novo-hamburgo-no-vale-do-sinos-3785199.htmlnos3785199.html Acesso em: 04 jul. 2013.

COSTA, Sérgio Roberto. Dicionário de Gêneros Textuais,.Belo Horizonte: Autêntica,2012.

DOLZ, J. et SCHNEUWLY, B. Gêneros Orais e Escritos na Escola (Tradução provisória de Roxane Rojo).São Paulo:Mercado da Letras,2004.

GUIMARÃES, Ana M.DE M.et al. Gêneros de texto no dia-a-dia do Ensino Fundamental.Campinas: Mercado de Letras, 2008.

GUIMARÃES, Ana M.de M.\& KERSCH, Dorotea F. Projetos didáticos de gênero na sala aula de Lingua Portuguesa, São Paulo:Mercado das Letras, 2012.

HORIZONTE DEBATE. Bullying e violência nas escolas. YouTube. Disponível em: http://www.youtube.com/watch?v=vUkymA6IgNw Acesso em: 04 jul. 2013

MARCHUSCHI, Luis Antônio. A produção Textual Análise de Gêneros e Compreensão. Parábola Editorial, 2008. 